\title{
Curso de Licenciatura em Matemática a Distância: Um Relato de Experiência
}

\author{
Gertrudes Aparecida Dandolini - UFPEL - ggtude@ gmail.com* \\ João Artur de Souza - UFPEL - jartur@ gmail.com ${ }^{* *}$ \\ João Carlos Roedel Hirdes - UFPEL - joaocrh@ gmail.com ${ }^{* * *}$ \\ Iuri Barcelos Pereira Rocha - UFPEL - iuri_rocha@gmail.com ${ }^{* * * *}$ \\ Paulo Moacir Galeão da Rosa Junior - UFPEL - paulomoacir.junior@ gmail.com ${ }^{* * * * *}$
}

Resumo: Este artigo apresenta relatos sobre o andamento do Curso de Licenciatura em Matemática na modalidade a distância da Universidade Federal de Pelotas (UFPEL), discutindo aspectos relacionados à participação dos alunos e ao andamento das disciplinas nos três pólos onde o curso está sendo oferecido. Apresenta, ainda, a forma como a capacitação dos alunos e tutores foi realizada e também a acolhida feita aos estudantes como fonte motivadora no processo de aprendizagem colaborativa. Relata, por fim, os aspectos relacionados com a estrutura administrativa utilizada para o atendimento ao aluno, bem como a gestão do curso.

Palavras-chave: Educação a Distância; Licenciatura em Matemática; Gestão em Educação a Distância.

\section{E-learning mathematic course: A report of experience}

\begin{abstract}
This article presents some descriptions about the execution of the graduation course of mathematics education in the modality the distance of the Universidade Federal de Pelotas (UFPEL). It discusses aspects related to the participation of the students and the course of the disciplines in the three cities where the course is being offered. It presents still how students and guardians were qualified for the course and also the way students were been welcome as reason for motivation for collaborative learning experience. It presents, at last, aspects related to the administrative structure utilized for attending to students needs, as well like the management of the course itself.
\end{abstract}

Keywords: E-learning; Mathematics education; distance teaching management.

\footnotetext{
* Professora Adjunta, Doutora em Engenharia de Produção, UFPel, Coordenador do Curso de Licenciatura em Matemática à Distância, Universidade Federal de Pelotas, http://www.ufpel.edu.br/clmd ${ }^{* *}$ Professor Adjunto, Doutor em Engenharia de Produção, UFPel, Coordenador do Curso de Licenciatura em Matemática, Universidade Federal de Pelotas, http://www.ufpel.edu.br/clmd

*** Aluno do Curso de Licenciatura em Matemática, UFPel, membro da equipe multidisciplinar do LEMAD, http://www.ufpel.edu.br/clmd

${ }^{* * * *}$ Aluno do Curso de Licenciatura em Matemática, UFPel, membro da equipe multidisciplinar do LEMAD, http://www.ufpel.edu.br/clmd

${ }^{* * * * * *}$ Aluno do Curso de Licenciatura em Matemática, UFPel, membro da equipe multidisciplinar do LEMAD, http://www.ufpel.edu.br/clmd

V. $4 \mathrm{~N}^{\circ} 1$, Julho, 2006
} 


\section{Introdução}

Apresentar um relato dos trabalhos realizados para estabelecer a Educação a Distância como uma modalidade de ensino viável à UFPEL não é uma missão trivial. A princípio, muitas experiências eram locais e não havia uma equipe capacitada para absorver todas as tarefas a serem cumpridas. Além disso, a inclusão de uma nova modalidade de ensino provoca discordâncias nas estruturas vigentes, pois se fazem necessárias mudanças substanciais. Muitas instituições estão construindo ainda uma estrutura adequada e na UFPEL não é diferente: se está trabalhando para criar um espaço em que educação a distância possa ser tratada como um todo.

Até o momento, apenas a equipe da Matemática logrou a formação multidisciplinar indispensável e, com a colaboração de colegas de outras áreas, conseguiu promover as discussões necessárias para preparar um projeto e submetê-lo aos editais do MEC. O êxito da equipe pode ser observado na própria página do Ministério da Educação, onde constam as classificações dos projetos submetidos. Mesmo com esta vitória, entretanto, a equipe tem encontrado algumas dificuldades para executar todas as tarefas envolvidas no processo e está em fase de aprendizagem e aperfeiçoamento, o que não nos isenta do dever de contribuir com os colegas das diversas áreas interessados na $\mathrm{EaD}$ através de um relato simples, mas substancial, das atividades desenvolvidas.

Vamos começar, então, com uma frase que resume o início dos nossos trabalhos: "novos meios necessitam de novas motivações e responsabilidades".

\section{Histórico}

Faremos, inicialmente, um breve histórico com o intuito de mostrar o caminho a ser percorrido por uma Instituição de Ensino Superior para alcançar o objetivo de fornecer cursos a distância.

A UFPEL iniciou sua caminhada no ensino a distância preparando o projeto de oferta do Curso de Licenciatura em Matemática a Distância (CLMD). O projeto foi encaminhado ao MEC e aprovado pelo Conselho Universitário da UFPEL. Na seqüência, a universidade foi credenciada a oferecer cursos de graduação a distância. O caminho que a UFPEL percorreu junto ao MEC vai da submissão da proposta ao aceite da criação do curso, consoante com as necessidades da região sul do Brasil.

$\mathrm{Na}$ preparação dos projetos foram feitas, por parte dos professores, viagens de visita a outras instituições que estavam em processo de oferecer cursos a distância ou que já ofereciam, a fim de analisar e discutir seus projetos pedagógicos específicos e conhecer a estrutura de trabalho. Com essas análises surgiram as discussões sobre a forma de capacitação dos envolvidos no processo, incluindo professores, tutores, alunos e até os secretários. A integração das áreas e a multidisciplinaridade é fator indispensável, pois as mídias não fazem nada sem que sejam usadas devidamente. Muitas reuniões foram realizadas, muitos contra-argumentos foram necessários para analisar o que pode ser feito a distância e como as tecnologias podem ser usadas no processo de ensinoaprendizagem a distância.

Todo o trabalho de conscientização foi difícil e, ainda hoje, são necessárias muitas discussões, pois a capacitação é contínua e as tecnologias são desafiadoras. Tudo tem que ser apropriadamente analisado e configurado para o sucesso da execução. 
O CLMD nasce conscientizado da necessidade de qualificar os processos de escolarização que compõem os cotidianos das escolas da rede pública, priorizando a formação/qualificação/atualização das práticas docentes.

Quando tratamos de Matemática, historicamente há uma visão de que esta é a ciência mais difícil de ser compreendida de todo o currículo de formação da educação básica no Brasil. Esse fato é extremamente preocupante e facilmente comprovado, pois desde 1991 o Ministério da Educação vem obtendo informações sobre o desempenho dos alunos de nossas escolas, por meio do Sistema Nacional de Avaliação da Educação Básica (SAEB).

Diante desse problema presente na educação brasileira, viemos com a meta de formar docentes com uma visão qualificada e eficiente para o ensino da Matemática.

Em termos de estrutura física, o CLMD é ofertado pela UFPEL em três pólos, correspondentes a três cidades da região sul do Rio Grande do Sul: Canguçu, Turuçu e Jaguarão. Estes pólos são estabelecidos em parceria com as respectivas prefeituras. Enquanto a universidade provê o curso, os professores, os materiais didiáticos, etc., as prefeituras têm que disponibilizar locais para laboratório, sala de aula, biblioteca, além de tutores para auxiliar no acompanhamento dos alunos.

A trajetória do nascimento do CLMD teve sua consolidação em dezembro de 2005, quando foi realizado o primeiro processo seletivo. Esse processo foi específico para o curso e foi realizado ao mesmo tempo para os três pólos de abrangência. $\mathrm{O}$ processo seletivo teve por objetivo avaliar conhecimentos e habilidades específicas necessárias para que os alunos ingressem no CLMD.

No próximo tópico abordaremos o perfil do nosso aluno, contextualizando o ambiente onde vivem e o quanto é importante para o desenvolvimento da aprendizagem a troca de cultura específica de cada cidade/pólo.

\section{Os alunos do CLMD}

Trabalhamos com três cidades/pólos da região sul do estado do Rio Grande do Sul que, apesar de pertencerem à mesma região, possuem características próprias. Isso nos mostra que cada pólo possui um tipo de aluno, pois estes vivem em diferentes ambientes.

Primeiro fato a ser lembrado é que os nossos alunos são portadores do título do ensino médio ou equivalente, uma exigência comum aos cursos de graduação.

Nos três pólos, os discentes, em sua maioria, têm idade superior a 24 anos, não têm curso superior, trabalham na iniciativa privada ou pública em tempo integral, têm pouco tempo para se dedicar ao curso, têm acesso à internet em casa ou no trabalho, conforme pode ser visto nos histogramas abaixo (Figuras de 1 a 6 ).

Um fato importante a ser considerado junto com estes dados, e esperamos comprová-los no futuro, é que estamos trabalhando com alunos que não são recém egressos do ensino médio e que, além disso, têm uma história de compromisso e responsabilidade nos seus trabalhos. O seu tempo livre não é muito e assim tem-se de incentivar a interação para a construção do conhecimento, promover trabalhos em grupos e estimular o compromisso com os horários destinados ao curso.

O curso ainda está em seu início, porém percebe-se que a relação entre o compromisso de ter seus horários e aulas presenciais é pouco compreendida. Precisa-se a todo o V. $4 \mathrm{~N}^{\circ} 1$, Julho, 2006 
momento lembrá-los do compromisso do estudo em grupo e que o professor está num papel de orientador. Certos de que a relação entre um curso presencial e o virtual é bastante incipiente, precisamos apresentar esta nova modalidade com todo o entusiasmo e competência. Os momentos presenciais oferecidos possuem uma aceitabilidade extraordinária, ou seja, a importância do contato ainda é permanente e persistente, mas esperamos que o tempo transforme os hábitos e que o papel de orientador possa ser usado tranqüilamente no decorrer do curso.
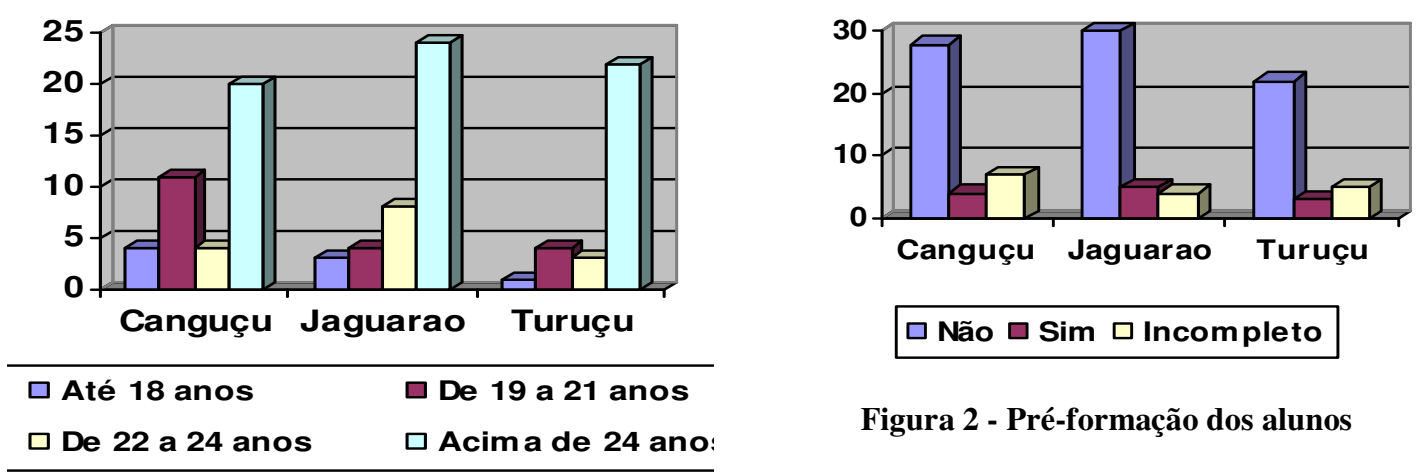

Figura 2 - Pré-formação dos alunos

Figura 1 - Faixa etária dos alunos do CLMD

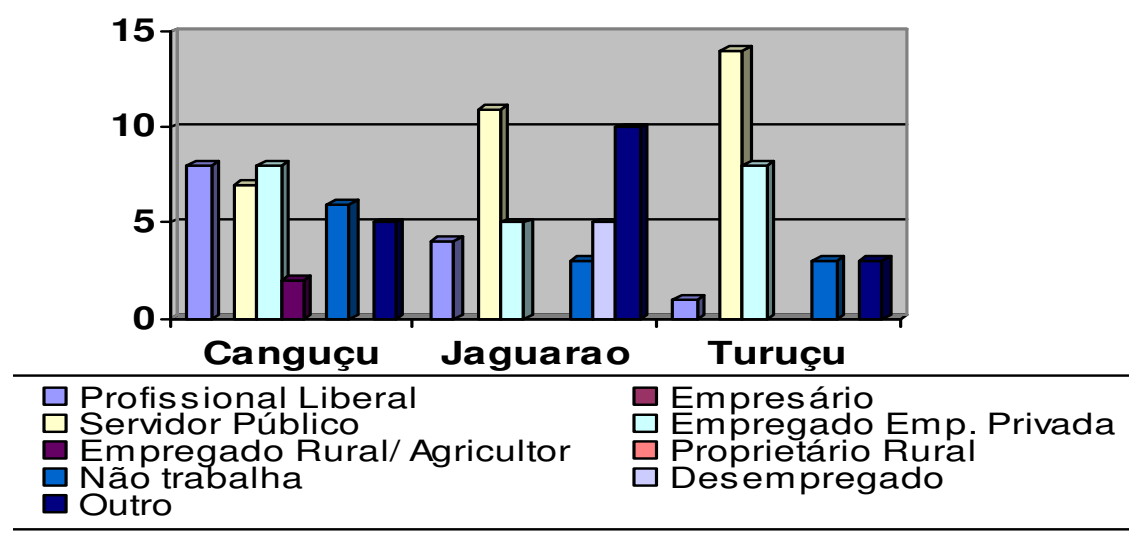

Figura 3 - Principais ocupações dos alunos

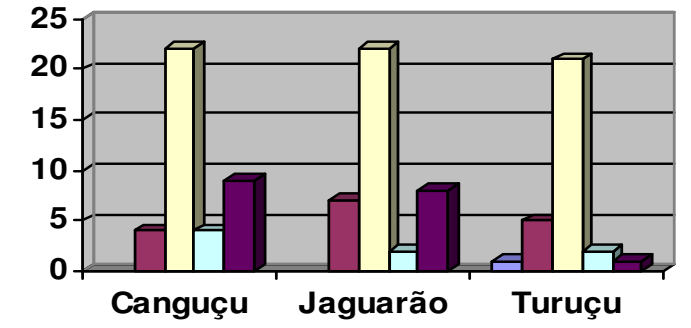

$\square$ Nos últimos anos $\square$ Sim, tempo parcial $\sqsupset$ Sim, tempo integral não sei

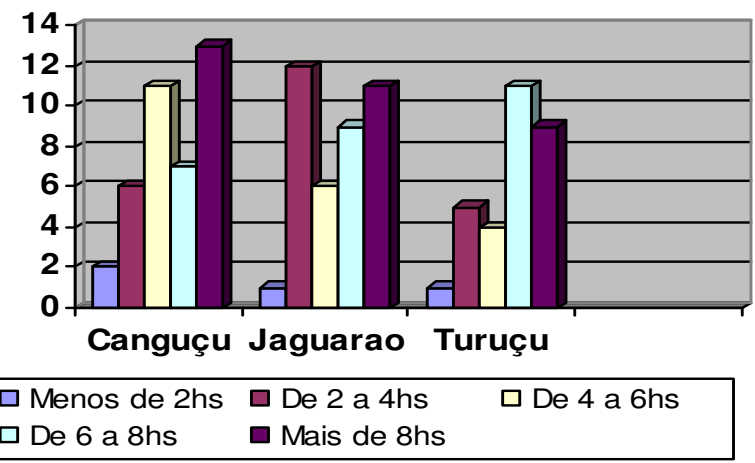

V. $4 \mathrm{~N}^{\mathrm{o}}$ 1, Julho, 2006 
Figura 4 - Destinação de tempo pretendida para o trabalho

Figura 5 - Tempo que destinará ao estudo no curso

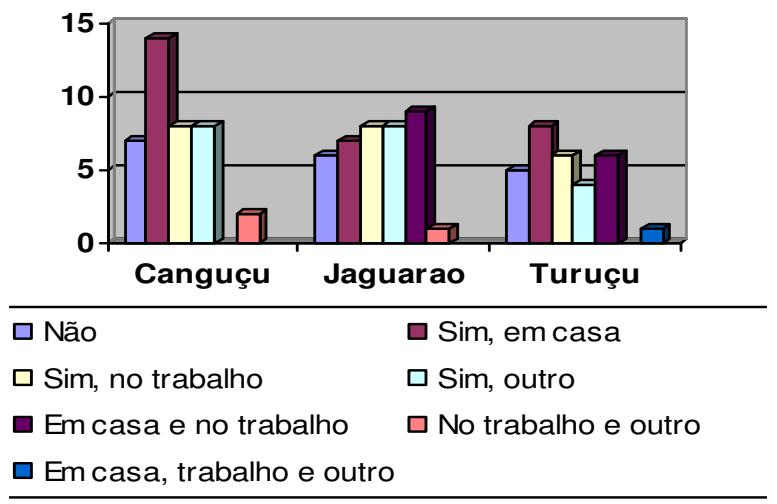

Figura 6 - Acesso a internet

\section{A Capacitação}

Compartilhamos das preocupações de Moran (2004),

"Uma outra atividade importante nesse momento é a capacitação para o uso das tecnologias necessárias para acompanhar o curso em seus momentos virtuais: conhecer a plataforma virtual, as ferramentas, como se coloca material, como se enviam atividades, como se participa num fórum, num chat, tirar dúvidas técnicas. Esse contato com o laboratório é fundamental porque há alunos pouco familiarizados com essas novas tecnologias e para que todos tenham uma informação comum sobre as ferramentas, sobre como pesquisar e sobre os materiais virtuais do curso."

pois não se consegue trabalhar com o aluno adequadamente se fatores externos ao conteúdo atrapalham. Uma boa capacitação é de suma importância para obter êxito na educação a distância.

Assim, antes do início das aulas, o CLMD promoveu diversas atividades visando à integração dos alunos entre si e a sua preparação para essa nova modalidade de ensino.

\subsection{Curso de Capacitação de Alunos para Ensino a Distância}

O sucesso do processo educativo a distância está diretamente relacionado com a competência do aluno enquanto participante do mesmo, no qual seu conhecimento seja elaborado, na sua maior parte, por si próprio. Esse aluno deve ser seguro de si em seu trabalho, deve ter consciência de que ele é o responsável pelo seu estudo. Além dessas orientações, em termos de competências e de sua segurança como discente, entende-se também que o mesmo deve portar-se criticamente frente a situações com as quais venha a se deparar.

Considerando as dificuldades de aprendizagem e o perfil cultural dos alunos e da 
comunidade, percebeu-se a necessidade de prepará-los, visto que grande parte apresentava dificuldade com relação ao uso de tecnologias, nunca tinha acessado um ambiente virtual de aprendizagem e desconhecia a modalidade de ensino a distância.

Em virtude disso, os alunos do CLMD foram submetidos ao Curso de Capacitação de Alunos para Ensino a Distância (CAPED), que foi desenvolvido utilizando-se do ambiente virtual de aprendizagem MOODLE. No primeiro módulo, a concentração dos estudos deu-se no aspecto prático-pedagógico, tanto os relacionados às necessidades de um Curso de Licenciatura a Distância quanto ao conhecimento das mídias utilizadas para este fim, abordando questões relacionadas às mídias na educação, à metodologia de ensino a distância, o papel dos alunos, do professor e dos tutores. No segundo momento, e enfoque foi dado principalmente no uso do ambiente virtual de aprendizagem MOODLE e nas suas funcionalidades no que diz respeito à interatividade e dinâmica de trabalhos que promovam a aprendizagem. distância.

Ambos os módulos foram realizados parte de forma presencial e parte a

Os resultados obtidos no transcorrer deste curso foram extremamente satisfatórios no que tange à participação, integração e aprendizado dos participantes. Isso se comprova no fato de que, após a execução do CAPED, os alunos continuaram a se comunicar e esclarecer dúvidas através do ambiente MOODLE.

Com o curso de capacitação, percebeu-se também que os alunos estavam muito ansiosos para o início das aulas e bastante motivados, porém, devido à greve de 2005, a data de início das aulas era ainda incerta. Para não perder essa motivação e promover o desenvolvimento do trabalho em equipe e de uma comunidade de aprendizagem on-line, o que consideramos extremamente importante num curso a distância e é bastante enfatizado por Palloff e Pratt (2004), oferecemos-lhes mais um curso a distância utilizando o ambiente de aprendizagem, o qual descrevemos a seguir.

\subsection{Curso Estórias, Histórias e Desafios}

Entre os objetivos do ensino a distância está a formação de uma nova mentalidade no uso de tecnologias com relação às formas de aprendizagem e desenvolvimento de um processo cooperativo de aprendizagem. Palloff e Pratt (2004) são enfáticos quando tratam da importância de criar uma comunidade de aprendizagem on-line, para que tenhamos sucesso em um curso a distância. Apesar de o aluno apresentar uma grande autonomia na construção do conhecimento, o trabalho em equipe é fundamental. Cada um deve dar a sua contribuição.

Dessa forma, com o objetivo de instigar essa colaboração, participação e integração entre os alunos e com o CLMD foi criado o curso Estórias, Histórias e Desafios, que consiste num espaço aberto para debates informais sobre matemática, relatos de experiências pessoais e desafios.

Embora não se tenha exigido a obrigatoriedade de participação nesse curso, a maioria dos alunos participou de forma ativa, inclusive na construção das atividades.

\section{CLMD como funciona}

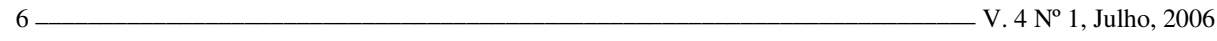




\subsection{Infra-estrutura dos Pólos}

A fim de alcançar a perfeita fusão entre educação a distância e qualidade em educação, o CLMD organiza-se em pólos tecnológicos, cada um localizado em uma diferente cidade da região sul. Esses pólos são estabelecidos em escolas das respectivas cidades e são constituídos por:

- laboratório informatizado (computadores, servidor, webcam, impressora, scanner, internet rápida), em que os alunos se reúnem para entrar no ambiente de aprendizagem, realizar pesquisas na internet, entrar em contato com os tutores e professores;

- sala de aula (para aulas presenciais);

- biblioteca com livros didáticos relevantes, para que os alunos possam consultar sempre que necessário e aprofundar-se, assim, em seus estudos;

- materiais concretos para a disciplina de Laboratório no Ensino de Matemática.

Além disso, cada pólo possui um ou dois tutores (denominados tutores dos pólos) licenciados em Matemática e um coordenador. Os tutores dos pólos acompanham de perto os alunos, as suas dúvidas e os avanços de cada estudante, e prestam toda a assistência necessária, proporcionando o vínculo pessoal e afetivo tão indispensável para o bom aproveitamento dos estudos. O coordenador do pólo é da área pedagógica e além de prestar assessoria é responsável pela organização administrativa do pólo. Nos três pólos os tutores e coordenadores trabalham de forma colaborativa, um complementando o trabalho do outro.

\subsection{Infra-estrutura da Sede}

$\mathrm{Na}$ sede, além da coordenação e secretaria, comum aos cursos presencias, temos também o Laboratório de Ensino de Matemática a Distância (Nunes et al., 2005) responsável pela produção de todo material didático (impresso, vídeos, sites, ...) onde trabalha uma equipe multidisciplinar, a sala de aula a distância para gravar vídeos e vídeo conferências, sala de estudos onde são realizadas as discussões sobre produção do material didático e a sala de tutoria, onde os tutores da sede e professores prestam o atendimento síncrono e assíncrono aos alunos.

Para cada disciplina há um professor responsável e um tutor (tutor da sede) que são encarregados pela execução da disciplina, atendimento aos alunos e assistência aos tutores do pólo. Esses tutores são professores licenciados em Matemática e foram escolhidos por intermédio de processo seletivo.

$\mathrm{Na}$ prática, os tutores da sede trabalham de forma integrada e auxiliam em todas as disciplinas, embora cada um tenha uma disciplina sobre a qual é responsável. O tutor da sede controla o recebimento das tarefas, corrige e devolve o parecer aos alunos, auxilia o professor responsável na elaboração e correção das provas e trabalhos, na preparação e execução das aulas presencias, e presta atendimento aos alunos.

O sistema de tutoria on-line é muito procurado pelos alunos, principalmente à noite.

\subsection{Comunicação}

V. $4 \mathrm{~N}^{\circ} 1$, Julho, 2006 
Nosso curso tem utilizado a mídia impressa, textos digitais e o ambiente de aprendizagem MOODLE como ferramentas básicas, mas a interatividade tem proporcionado uma aprendizagem colaborativa apropriada à continuidade:

Até agora temos ou cursos de sala de aula ou cursos a distância criados e gerenciados por grupos em núcleos específicos, pouco próximos da educação presencial. É importante que os núcleos de educação saiam do seu isolamento e se aproximem dos departamentos e grupos de professores interessados em flexibilizar suas aulas, que facilitem o trânsito entre o presencial e o virtual (MORAN, 2003, p. 45)

Cabe salientar que o professor do momento presencial é o mesmo do momento a distância, ratificando mais uma vez a afirmativa de Moran sobre o peso da sala de aula ainda fazer a diferença, precisando ser mais bem trabalhado pela gestão acadêmica.

Os encontros presenciais com os professores ou tutores da sede são realizados todos os sábados, um turno para cada disciplina, porém os alunos têm solicitado mais aulas presenciais, mostrando que ainda estão presos à modalidade presencial. Ainda assim, o projeto é ir trabalhando isto devagar. Alguns alunos já se conscientizaram do que significa um curso a distância e nos ajudarão no processo de conscientização dos outros.

Dispomos de diversas ferramentas para a comunicação com os alunos, como: telefone, e-mail, fóruns, chats, msn e skype. Os mais utilizados até o momento pelos alunos são: os fóruns dentro do ambiente de aprendizagem, o msn e o skype.

Além de buscar acessoria com os tutores, os alunos estão criando grupos de estudos. A mensagem a seguir foi retirada do fórum social do nosso ambiente de aprendizagem e é um relato de uma aluna, mostrando o quanto facilita trabalhar em grupo:

Acabei de resolver as tarefas desta semana, resolvi em grupo, foi muito bom, pois cada um sabe um pouco e ajuda os outros, conseguimos fazer a grande maioria, fomos debatendo e chegando as respostas. Acredito que os exercício são bem puxados, mas em grupo ameniza a situação.

É isso...

Boa sorte e bom estudo a todos. (Amélia)

A partir dessa mensagem, a tutora do pólo, junto com os alunos, começou a organizar o grupo de estudos.

Alguns grupos se reúnem no próprio pólo e outros na casa de um de seus membros. Como na região sul o inverno é bastante rigoroso, os estudantes alegam que trabalhar na casa de algum colega é mais aconchegante e mais produtivo e dizem: "aqui temos uma mesa enorme, muitos livros, internet para entrar em contado com os tutores e professores, além de bolacha, café, mate e lareira acessa".

A eficiência do trabalho em grupo está se comprovando em nosso curso, pois os alunos que estão estudando desta forma ou que estão sempre em contato com os tutores estão se destacando em relação aos demais.

\section{Análise do desenvolvimento}


Com a autorização das Universidades Federais para oferecerem ${ }^{1}$ cursos na modalidade a distância, em caráter experimental, várias pesquisas têm sido publicadas e a nossa experiência vem ao encontro do que a UFPEL, mais especificamente o CLMD, vem realizando para tornar o seu curso um modelo bem sucedido.

Temos observado que o planejamento para execução de curso é de extrema importância, pois estamos trabalhando, no momento, com três pólos. Ao mesmo tempo em que devemos nos preocupar em oferecer os mesmo serviços, devemos levar em consideração as realidades diferentes. Existe uma concorrência entre os alunos dos três pólos e eles ficam cobrando atendimento igual. Isto é difícil, pois um mesmo professor não pode atuar ao mesmo tempo nos três pólos. Para superar isto, estamos trabalhando na implantação do sistema de vídeo conferência e na elaboração de mais vídeo aulas.

É importante ressaltar que os relatos apresentados são parciais e merecem ser ampliados e continuados por um tempo maior, como prevê a pesquisa. Entretanto, foi possível verificar a necessidade e a importância de instrumentos de avaliação continuada para melhor direcionar ações pioneiras, principalmente as que envolvem diferentes modalidades de ensino, como é o caso da educação a distância. Os dados demonstram que os problemas são mais bem enfrentados a partir da intervenção de uma gestão mais envolvida com instrumentos de avaliação contínuos e abrangentes.

A satisfação dos alunos está diretamente ligada à eficiência e eficácia da gestão do programa de educação a distância e à aceitação dos instrumentos de acompanhamento e planejamento de ações. A qualidade do programa aqui analisado está diretamente relacionada à capacidade de intervir em tempo real e com instrumentos variados, suprindo as necessidades dos alunos.

A qualidade da educação está relacionada não só com a satisfação do aluno, mas também com a satisfação das demais partes envolvidas no processo, como professores, tutores, monitores, técnicos, funcionários e comunidade local, que podem também ser objeto de futuros estudos para medir o grau de satisfação e o perfil dos pólos para a preparação de materiais direcionados.

É importante lembrar que na educação existem muito mais pessoas envolvidas que apenas alunos e que os outros participantes no processo devem proporcionar aos gestores informações que venham a auxiliar no desenvolvimento local e na oferta do curso.

Também vale lembrar que a experiência adquirida na oferta do curso a distância deve imediatamente ser repassada aos cursos presenciais, pois o uso das tecnologias é uma realidade e não pode mais ser desprezada. Não podemos esquecer que os conteúdos tratados no curso presencial e no curso a distância são os mesmos, apenas a forma de abordá-los é que é modelada para a metodologia adequada a cada realidade.

\section{Referências Bibliográficas}

MORÁN, J. M. Mudar a forma de ensinar e de aprender com tecnologias - transformar as aulas em pesquisa e comunicação presencial-virtual. Disponível em: <http://www.eca.usp.br/prof/moran/uber.htm>. Acesso em: 10 abr. 2004.

MORAN. José Manuel. Contribuições para uma pedagogia da educação on line. In: SILVA, Marco (Org.) Educação on line: teorias, práticas, legislação, formação corporativa. São Paulo: Loyola, 2003.

\footnotetext{
${ }^{1}$ Portaria no 873, publicada no Diário Oficial da União de 11/04/2006. V. $4 \mathrm{~N}^{\circ} 1$, Julho, 2006
} 
NUNES, Elton Luiz Vergara; SOUZA, João Artur de; DANDOLINI, Gertrudes Aparecida. Laboratório de Ensino de Matemática a Distância. Renote - Revista Novas Tecnologias na Educação, Porto Alegre, v. 3, n. 1, p. 1-7, 2005.

PALLOFF, Rena M. e PRATT, Keith. O Aluno Virtual: Um guia para trabalhar com estudantes on-line. Tradução Vinicius Figueira. Porto Alegre: Editora Artmed, 2004. 216p. 